\title{
The Construction of the Curriculum System of Teaching Chinese to Speakers of Other Languages for Undergraduate Students-A Case Study on Zhejiang Province
}

\author{
Yong $\mathrm{Wu}$ \\ The English Faculty, Zhejiang Yuexiu University of Foreign Languages, Shaoxing, China
}

\begin{abstract}
With the rapid development of the Chinese economy, people are becoming interested in learning Chinese. Courses on teaching Chinese to speakers of other languages (TCSOL) have been gaining attention. However, given that TCSOL is new area of study, problems have emerged, such as conflicting perspectives in the curriculum for undergraduate students. To strengthen the construction of the undergraduate curriculum of the TCSOL system and to properly train TCSOL learners, 448 participants were invited to fill out a questionnaire and 40 TCSOL teachers and undergraduate students in Zhejiang Province were interviewed. By investigating and analyzing the current landscape of professional development, the four major problems in the construction of the professional curriculum system are discussed. Suggestions for the faculty and school administrators are also proposed.
\end{abstract}

Index Terms - undergraduate, University, TCSOL, curriculum system, construction

\section{INTRODUCTION}

With the development of economic globalization, the international community is giving more attention to China. An increasing number of people are becoming interested in Chinese language and culture, and the "Chinese language craze" has emerged worldwide. As a major, teaching Chinese to speakers of other languages (TCSOL) mainly aims at teaching Chinese language and cultural communication to foreigners.

Since 2007, TCSOL has achieved leapfrog development (Deng, 2018). TCSOL has become a promising major and received national attention. According to statistics, in 2018, 395 colleges and universities opened the undergraduate major of TCSOL in China. A total of 63,933 TCSOL undergraduate students have enrolled in Chinese universities since 2015 (Ning, 2018). However, due to the high enrollment rate, TCSOL undergraduates face high employment pressure (Wen, 2019). Although colleges and universities are the leading institutions for international students to study in China, most teaching positions have no vacancy for undergraduate students of TCSOL. Even if positions are opened occasionally, undergraduate students do not have a competitive edge over postgraduate students of TCSOL, and some undergraduates will not meet recruitment requirements. Despite a high demand for TCSOL teachers overseas, only a few outstanding undergraduate students meet the requirements of the "International Chinese Teachers Volunteer Program" by the Office of Chinese Language Council International (HANBAN) (Guo, \& Sun, 2016).

Moreover, most TCSOL teachers only have a temporary job according to Chinese teacher volunteers who have one-year employment contracts, and more than three years of service is not allowed in principle (Wang, 2017). On the one hand, these undergraduate students of TCSOL cannot fundamentally solve the employment problem and have to face the embarrassment of "unemployment upon return." On the other hand, a short-term overseas working experience cannot bring extra advantages to their employment. Most job opportunities for them are Chinese language training institutions for foreigners and some international schools. Hence, the job opportunities for TCSOL undergraduate students are limited.

Since 2007 the Chinese government has allowed universities to offer TCSOL as a master's degree program (Liu, 2016). Issues have triggered a boom in the study of international Chinese language education because the academic circle started to turn their interest toward the curriculum of master's degree students rather than that of undergraduate students of TCSOL. Moreover, doubts and criticisms have been raised on whether offering TCSOL majors at the undergraduate level is necessary and whether the current TCSOL majors simply combine the Chinese language curriculum with the foreign language curriculum for undergraduate students. Therefore, examining the whole process of developing the undergraduate curriculum of TCSOL is essential to answer these questionings. The curriculum system is the leading carrier for undergraduate students' TCSOL teaching, which is also one of the core contents of the teaching activities (Yang, 2019). Hence, the construction of the curriculum system is essential work in TCSOL education. A curriculum is directly related to the construction of undergraduate students' knowledge, and the development of their abilities. By focusing on undergraduate students' curriculum and targeting the TCSOL undergraduate students' 
development, the TCSOL curriculum system for undergraduate students will be optimized and updated.

In China, researchers have found the importance of the TCSOL curriculum for undergraduate students. Xing and Wan (2014) analyzed the new changes in the TCSOL curriculum for undergraduate students when they compared the new and old syllabi launched by the Ministry of Education. Shi (2019) noted problems in the adjustment of the TCSOL curriculum and proposed suggestions for the construction of the undergraduate course system of TCSOL. For instance, strengthening the cooperation among TCSOL teachers, seeking multidisciplinary cooperation, increasing the proportion of elective courses, reforming assessment methods, diversifying evaluation forms, and cultivating the profession are vital. Although this research opened minds for the adjustment of undergraduate students' curriculum system of TCSOL on the basis of their teaching experience, this study does not discuss in detail how to make the specific curriculum construction.

Wang (2011) pointed out that optimizing the teaching and professional skills of TCSOL undergraduate students is necessary, as well as focusing on the application of skill-based courses and innovative research-based elective courses. He used the metaphor "one body and two wings" to describe the curriculum system for undergraduate students of TCSOL. This metaphor means that the language course (Chinese and English) is the core position, which embodies the strengthening of Chinese and foreign bilingualism, and supplements courses such as Chinese and foreign literature, cultural exchange knowledge and skills, teachers' education skills, and quality. Although this research indicated three significant problems in the practice of undergraduate students' TCSOL education and proposed seven aspects to improve TSCOL teachers' training, no comprehensive explanation is found for the curriculum system. Moreover, Wang (2019) proposed some problems encountered in TCSOL mainly depend on teachers' own teaching experiences.

Peng (2014) proposed another curriculum system that focuses on the innovative international promotion of TCSOL undergraduate students' training on the basis of "second language acquisition theory" and three "key communication abilities." In his research, Peng discussed the integration of professional courses, highlighting the professional characteristics of "bilingual and bicultural" to set up the course of "culture plus language" to achieve the requirements of the development of TSCOL. Pan and Chen (2016) asserted that TCSOL undergraduate students' training model and reconstructed the curriculum system by emphasizing that strengthening practical teaching, highlighting TSCOL students' training and professional development. Zhao (2020) suggested that improving the English language (or other languages) abilities of students will be helpful for language teaching and cultural communication. Although this research tackles the aspects of TCSOL teachers' ability cultivation, it fails to comprehensively analyze other dimensions of TSCOL undergraduate students' cultivation, such as knowledge and self-development.

Li (2014) compared the TCSOL curricula for master's degree students and undergraduates. Li thought that the curriculum system construction of TCSOL for undergraduate students should reflect the development trend and pay attention to the combination of knowledge content, strengthen the curriculum setting of skills, emphasize the construction of the practical system, and highlight the overall design of cross-cultural awareness. Liu and Jian (2017).also proposed a model of "four modules plus one link" for the TCSOL curriculum system. He regarded the compulsory course as a guide, the core course as the foundation, and the elective course as the supplement. Although this model is more creative than previous models, it does not give suggestions on the relationship among each module and does not specify the number of teaching hours for each module.

The current findings on undergraduate students' curriculum for TSCOL are inconsistent. Hence, four research questions are proposed.

1. Do Chinese universities have a clear vision to develop the curriculum of TCSOL for undergraduate students in Zhejiang Province?

2. Is the current curriculum of TCSOL for undergraduate students suitable for students' development in Zhejiang?

3. Is the current curriculum of TCSOL for undergraduate students reasonable for students' assessment in Zhejiang?

4. Does the current curriculum of TCSOL for undergraduate students meet the market demand in Zhejiang Province?

\section{METHODOLOGY}

\section{A. Participants and Procedure}

A total of 448 students from 11 local universities in Zhejiang Province and 40 teachers and undergraduate students of TCSOL were involved in this research. Paper-and-pencil surveys were administered by the researcher during class, and semi-open interviews were conducted with undergraduate students of TCSOL.

\section{B. Data Analysis}

\section{The Professional Cognition from undergraduate students of TCSOL}

Although $67 \%$ of respondents have a clear concept of the professional cognition of TCSOL, 33\% of respondents do not have a clear idea about it. Figure 1 shows the need to increase publicity and expand the influence of undergraduate students of TCSOL to gain recognition in society. Moreover, $90 \%$ of respondents agreed that they would be international Chinese language teachers in the future who are good at language teaching and cultural communication. This result indicates that most respondents have understood the goal of complexity and application in TCSOL education. 


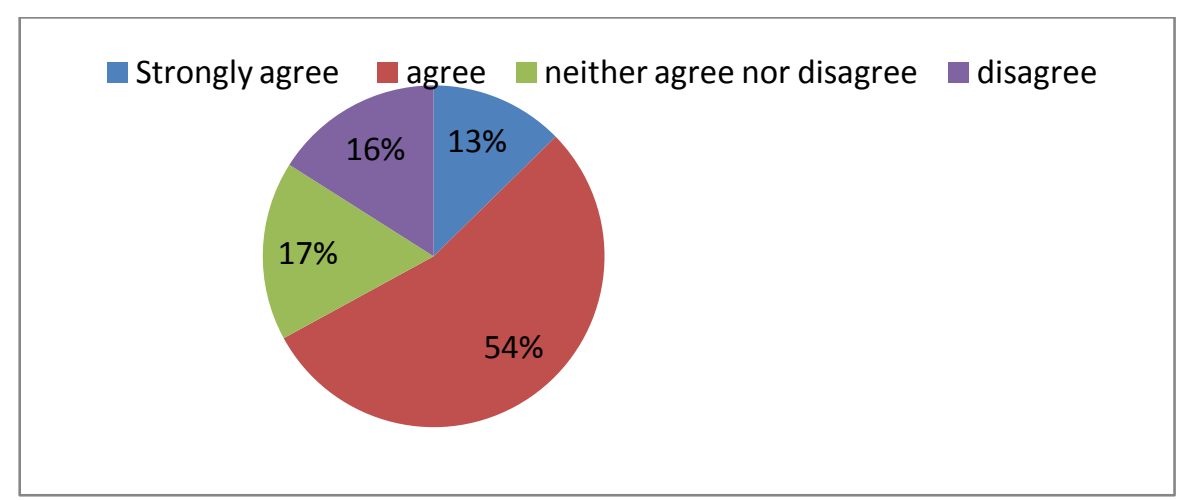

FIG. 1 Percentage of Professional Cognition from Undergraduate students of TCSOL

\section{Views on the Curriculum System of TCSOL}

According to Figure 2, $83.21 \%$ of respondents are satisfied or strongly satisfied with the courses offered by the undergraduate program of TCSOL, and $16.79 \%$ of respondents are dissatisfied or strongly dissatisfied. Although nearly half of respondents are not familiar with the curriculum and curriculum system of TCSOL, the undergraduate curriculum system of TCSOL is important for teachers' teaching and students' learning. It has excellent research value and practical significance.

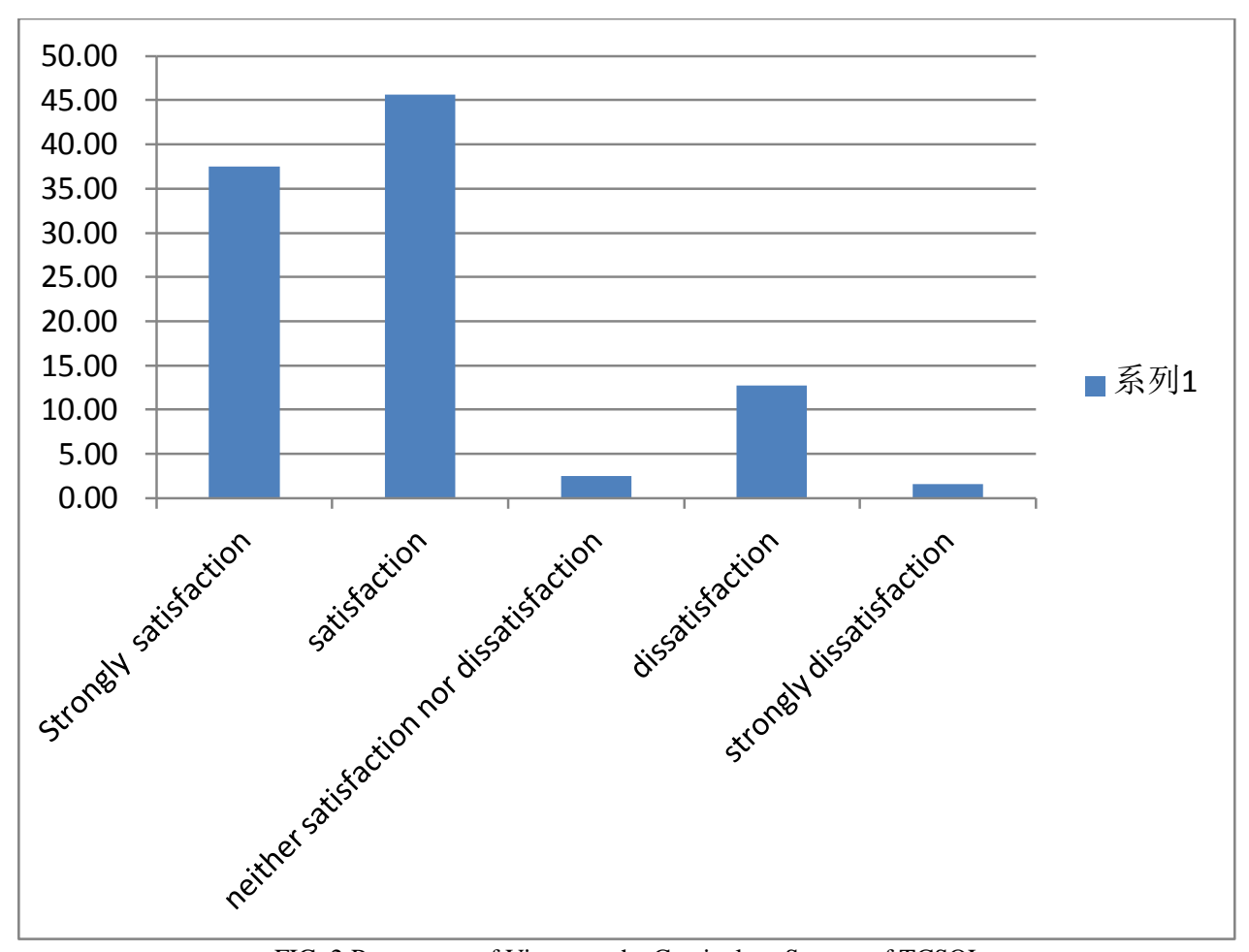

FIG. 2 Percentage of Views on the Curriculum System of TCSOL

\section{Views on undergraduate courses in TCSOL in their respective universities}

Figure 3 shows that $49.19 \%$ of respondents did not have a satisfactory attitude toward the curriculum of TCSOL in their universities, which indicates that the current TCSOL curriculum in local universities is not ideal and needs to be adjusted. More than one-third of respondents think that the deficiencies of the construction of undergraduate courses in TCSOL include: unclear training objectives, patchwork of courses, unreasonable structure, lack of a system, incomplete courses, insufficient content and knowledge involved in courses, unreasonable proportion of theoretical courses and practical courses, and unreasonable proportion of knowledge courses and skill courses. Besides, only approximately 30\% of respondents are satisfied with the total amount of class hours, the number of courses offered each semester, the weekly class hours of courses, and the order of courses offered in TCSOL. This result shows that undergraduate courses of TCSOL education need to be optimized and adjusted. 


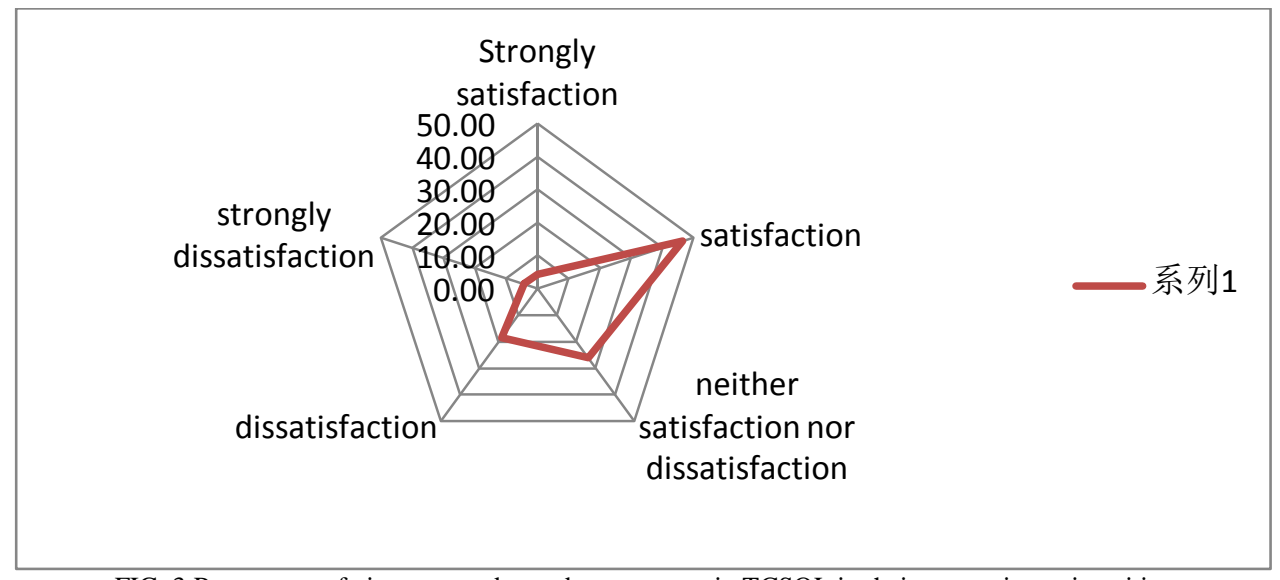

FIG. 3 Percentage of views on undergraduate courses in TCSOL in their respective universities

\section{Construction of undergraduate courses in TCSOL}

More than half of respondents hope to become teachers of Chinese as a foreign language in private schools and relevant institutions whether in China or overseas in the future. In addition, $46 \%$ of respondents hope to continue their studies and become professional researchers; primary and secondary school teachers; or teachers in language and cultural institutions. Vast job opportunities are available for undergraduate students of TCSOL. Therefore, considering different employment demands in course setting is necessary. Most respondents thought that they lack skills in teaching Chinese as a second language and the knowledge and ability needed for cross-cultural communication. Thus, they suggested the class hours for language teaching and cross-cultural communication training to be increased. Moreover, $82 \%$ of respondents hope to increase the proportion of cross-cultural communication courses and Chinese traditional culture courses.

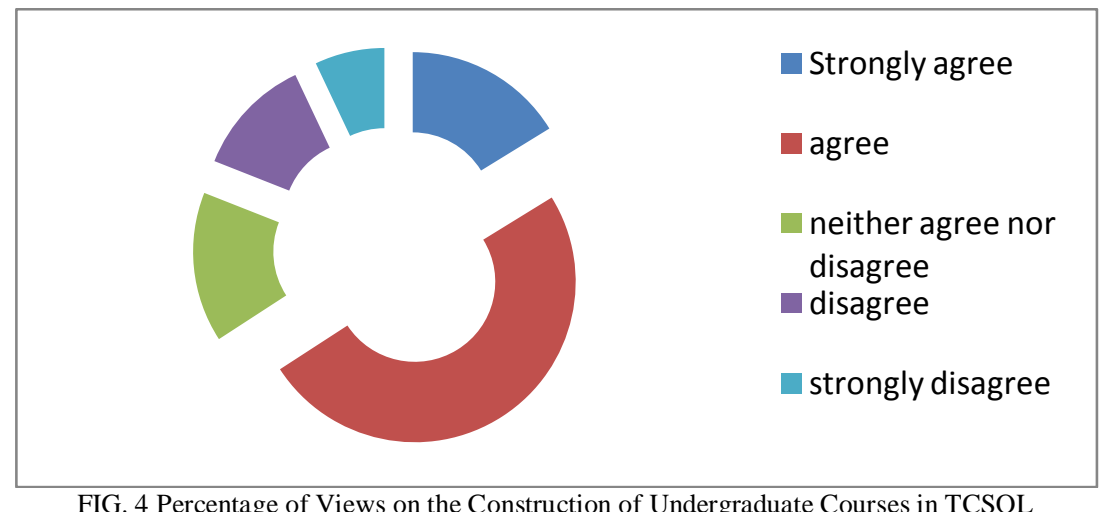

FIG. 4 Percentage of Views on the Construction of Undergraduate Courses in TCSOL

\section{Internship}

Approximately $87 \%$ of students think that starting their internship in the third year is appropriate because they could develop strong motivation to accumulate relevant knowledge and abilities during their freshman and sophomore years. In their fourth year, they could go back to class to enrich and reflect on themselves according to practice and their internship performance. More than $30 \%$ of respondents agree that internships should be arranged in the second semester of the third year. More than $55.68 \%$ of respondents thought that the period of internship in this major should be from three months to six months. More than $51.35 \%$ of respondents wanted to do overseas internships, and they wanted teachers to help them arrange such internships. Hence, university administrators should strengthen the overseas internship program and extend the number of Chinese teaching practice bases to provide more opportunities for undergraduate TCSOL students. 


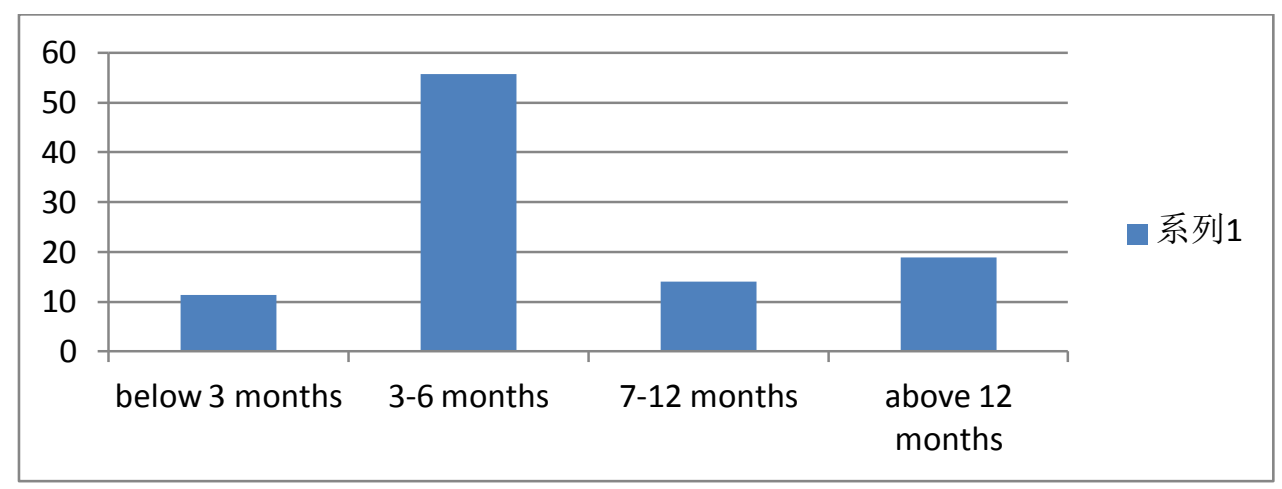

FIG. 5 Percentage of Views on Internship Duration

\section{RESULTS AND DISCUSSION}

\section{Q1: Do Chinese universities have a clear vision to develop the curriculum of TCSOL for undergraduate students} in Zhejiang Province?

Most Chinese universities have an accurate and clear vision to develop the undergraduate curriculum of TCSOL education, as shown in Figure 1. However, the curriculum setting of local universities in Zhejiang Province lacks foresight. The curriculum syllabus of TCSOL cannot adequately meet the needs of undergraduate students of TCSOL. The Ministry of Education has made a comprehensive exposition of the knowledge and abilities that undergraduate students of TCSOL should possess. However, in terms of the actual curriculum in local universities, thoroughly conducting and arrive at the objectives and requirements of TCSOL issued by the Ministry of Education for some local universities is difficult.

Measures should be adjusted to match the local conditions to develop the undergraduate curriculum of TSCOL. On the basis of the coordination development plan, the curriculum should also include a development route in line with international standards, and optimize the construction of undergraduate courses of TCSOL with regional characteristics.

Additionally, TCSOL teachers should maximize resources to build the courses for TCSOL undergraduate students and consider the characteristics of multidisciplinary, multi-faceted knowledge and multi-ability requirements when setting up the TCSOL curriculum system. Teachers should also pay more attention to the practical aspects of TCSOL, and practical courses should be added to the curriculum system. In addition to considering the characteristics of the major, the course system should consider the actual situation in universities, such as advanced subjects, geographical location, and teaching facilities. Universities in Zhejiang should incorporate the long cultural history of Jiangnan into the curriculum, whereas universities in Hangzhou can integrate calligraphy, Yue opera, and bamboo weaving into the curriculum system. The construction of a multidimensional interactive curriculum system of "Chinese plus international plus education" is the internal interaction of three elements. "Chinese" (language and culture) is the core and content of second language teaching, learning, and communication. "International" is the environment and region of Chinese as a second language education cultural exchange.

Furthermore, "education" is the way and method of Chinese learning or teaching internationalization and cultural exchange and communication. After the interaction of the three elements, six directions of "Chinese + education" (integrate Chinese education and Chinese communication), "Chinese + international" (integrate Chinese internationalization and international Chinese) and "international + education" (integrate international education and education internationalization) can be formed. Therefore, "three combinations" and "six directions" formed after the interaction of the three elements of "Chinese + International + education" constitute an interrelated whole, which should be the basic characteristics and essential attributes of Chinese international education. As a whole, these combinations embody the characteristics of TCSOL. In the second level of interaction between the single element of "Chinese + International + education" and the curriculum, "Chinese + Curriculum" includes Chinese language and culture and its related courses. Chinese (language + culture) courses solve the problem of "what to teach, to learn, and to broadcast." These courses interpret and grasp the complex needs of Chinese teaching and Chinese international education to ensure the quality of the core courses of Chinese language and culture; the construction of related course groups; and consolidate students' basic knowledge of Chinese language, learning, and culture. "International + Curriculum" includes foreign language and culture courses, cross-cultural communication courses, and international (domestic and foreign) courses to solve the problem of "where to teach, learn, and spread." "Education + Curriculum" includes the Chinese international education psychology curriculum, teaching method curriculum, and cultural communication curriculum. The education (classroom and practice) curriculum solves the problem of "how to teach, learn, and spread." The multidimensional interaction of the three levels in the course system of "Chinese + International + education" is multi-level and three-dimensional. The interaction is built around the necessary knowledge (Chinese language and culture teaching, learning, and communication), fundamental abilities (teaching, learning and communication methods of Chinese language and culture, teaching organization and classroom management, planning, marketing, and 
communication coordination), and core literacy (Chinese culture and cross-cultural communication, professional ethics, and professional development).

Q2: Is the current curriculum of TCSOL for undergraduate students suitable for students' development in Zhejiang?

The curriculum is reasonable, but the curriculum features are not distinctive according to Figure 2. The curriculum system of TCSOL for the undergraduate course should be composed of three major parts: knowledge courses, such as language, literature and culture and practical courses, such as teaching skills and methods, and foreign language courses. However, the curriculum system of many universities focuses on knowledge courses and foreign language courses, which do not highlight the nature, characteristics, and principles of TCSOL for undergraduate students. Most local colleges and universities open a series of courses, such as language, literature, and culture, but these courses do not show how to cultivate undergraduate students to become qualified TCSOL teachers. Moreover, the content of these courses generally lack the strategy and awareness of how to use the corresponding teaching content and teaching skills according to different countries and needs of the teaching objects. The content of these courses are not conducive to the construction of a reasonable knowledge structure for TCSOL students, nor can it meet the ever-changing needs of TCSOL.

Hence, the curriculum of TCSOL for undergraduate students should be closely related to the training objectives and requirements of the major. The realization of the training goal, which is students' mastery of the solid fundamental knowledge of Chinese, is related to the proportion of language courses. TCSOL teachers could open some courses, such as modern Chinese language, ancient Chinese language, and linguistics into the curriculum system. These courses can strengthen knowledge of history, culture, and literature in China and abroad. Moreover, considered "literature knowledge" reserve as a requirement courses matches courses such as "introduction to ancient Chinese literature," "modern and contemporary Chinese literature and foreign literature." These courses are closely combined with the training objectives and requirements of the TCSOL. In addition, marginalized or unrelated courses should not be offered. Therefore, in future course system setting, TCSOL teachers should ensure that the course and the professional training goal are aligned. The sequence and proportion of the curriculum will affect the professional training objectives and requirements. TCSOL teachers should consider the learning characteristics of students, the characteristics of the curriculum itself, teaching time, teaching difficulty, and other factors to set the sequence and proportion. Each TCSOL course needs to perform according to its objectives. Therefore, TCSOL teachers should not only optimize the basic knowledge of the reform course, but also assist each other, cooperate with relevant courses to cultivate critical capabilities, and develop together. Through the course combination, TCSOL students should improve core literacy as a whole, and deal with the relationship of various types of courses in every dimension.

Q3: Is the current curriculum of TCSOL for undergraduate students reasonable for students' assessment in Zhejiang?

The TCSOL curriculum is reasonable for students' assessment according to Figure 3. However, the relationship between each course is not clear, and the evaluation mechanism is not flexible. Many problems are encountered in the assessment for undergraduate students' TCSOL, such as paying little attention to the relationship between the theory and practice of the curriculum; the connection between disciplines; proportion of credit hours; and assessment method. Many professional compulsory courses or elective courses are usually not set up according to the uniqueness of TCSOL education but are rather based on the research direction or willingness of the teacher. These problems will affect students' knowledge, practical ability, and other aspects. These problems will affect whether they can adapt to the requirements of Chinese teachers at home and abroad, which will affect their future teaching careers. In the current assessment system of university teachers, the evaluation of teachers focuses on scientific research ability than their teaching ability, which drives many teachers to spend much time on scientific research; hence, the time and energy devoted to improving their teaching skills are limited. This situation has directly led many teachers to only teach the same course for several years, and the content of the course has remained unchanged. This situation will lead to the lack of novelty and timeliness of the course content, thus leading to the absorption of outdated knowledge by students, which may make them appear incompetent when they eventually teach. No guidance and evaluation exists for the direction of TCSOL for students' extracurricular activities and social practice.

Moreover, the proportion of major compulsory courses in the learning plan is significantly higher than that of major elective courses and major expansion courses. This imbalance will affect students' foreign knowledge reserve and practical ability, and will affect whether they can adapt to the requirements of Chinese teachers at home and abroad. One of the core qualities of excellent international Chinese language educators is to inherit and develop the unique traditional Chinese culture. With the increasing global demand for understanding, research, and learning Chinese, the spread of distinctive Chinese culture needs to be confident, self-conscious, and self-consistent with its language and culture. According to the Chinese Ministry of Education, one of the training requirements of undergraduate majors of TCSOL is to enable students to master Chinese history and culture and gain the essential understanding of international cultures. Thus, TCSOL teachers should realize that integrating culture into the curriculum system is advantageous. The contents of the cultural section should include not only traditional Chinese culture and traditional classics Chinese culture, but also modern Chinese culture, the introduction of foreign cultures, the comparison between Chinese and foreign cultures, and the distinctive regional culture of the place where the university is established. Only in this way 
can TCSOL teachers understand the distinctive ancient and modern cultures and gain cross-cultural awareness, to better spread Chinese language and Chinese culture worldwide.

Q4: Does the current curriculum of TCSOL for undergraduate students meet the market demand in Zhejiang?

Theory does not always meet the actual needs of society. Whether undergraduate students of TCSOL will be needed by society is an essential factor to measure whether the construction of a professional curriculum system is scientific and reasonable. In this research, three kinds of goals for undergraduate students of TCSOL are enumerated. The first goal is to train teachers of international Chinese language education at all levels and categories at home and abroad except universities (including secondary and primary schools, bilingual schools, and Chinese language training institutions). The second is to provide a stable and high-quality source of students for a higher level of Chinese international education. The third is to focus on the cultivation of talents who can implement the grand strategy of going global of Chinese culture and are competent for the management and service talents organized by Chinese language, culture exchange, and communication institutions. These three personnel training objectives require students to have vast knowledge reserve, practical teaching experience, and cross-cultural communication. The acquisition of knowledge, practical experience, and abilities can come from books and teaching practice. An analysis of the current curriculum system of TCSOL in local universities reveals that training projects of Chinese international education undergraduates in most universities are adjusted many times. In the adjustment of undergraduate students' curriculum, the social requirements have not been fully investigated. Only a few differences have been noted among undergraduate students of TCSOL in many universities. Teaching plans are not arranged according to the actual situation and characteristics of schools. More theoretical courses are offered than practical courses, and teaching form in a theoretical course is always classroom-based. Occasionally, practical courses are offered, but they only arrange teaching links, such as lectures and trial lectures in a single course without immersing into an actual TCSOL classroom. These problems will inevitably affect the increase of students' knowledge reserve, the growth of teaching practice experience, and the improvement of their abilities. Hence, cultivating Chinese international education talents to meet the requirements of the society is impossible.

Owing to valid reasons, the possibility of TCSOL undergraduate students to practice their teaching profession in China is relatively low. Many undergraduate students of TCSOL attempt to choose to work as civil servants in China, Chinese teachers in primary or secondary school, or in enterprises after graduation; only a few choose to work as TCSOL teachers in China and abroad. The employment outlook for undergraduate students reminds administrators, TCSOL teachers, and policymakers of colleges and universities to adjust the current curriculum properly. Set up the curriculum of TCSOL according to social requirements is necessary. Students can even be arranged in small classes for TCSOL training according to employment requirements, and students can be offered a unique curriculum according to the job market's needs. The market for Chinese language teaching in the field of fundamental TSCOL education is vast especially overseas, and the shortage of TCSOL teachers who are good at Chinese language teaching and cultural communication is serious. Therefore, local universities should set up relevant courses according to market demand to cultivate talents for TCSOL. Moreover, according to the Chinese social requirements and market rules, TCSOL teachers should actively explore new personnel training and self-development modes. For instance, to help institutions and employers perform targeted training, the training mode could be adjusted and conducted when undergraduate students are still in the third year. The training mode should be based on country needs, regional needs, or institutional needs. Meanwhile, joint training modes should be open in China and abroad for undergraduate, postgraduate, and doctorate students. Thus, colleges or universities need to construct distinctive characteristics of the curriculum system for undergraduate students of TCSOL.

\section{Conclusions}

This research mainly explores the current situation of the curriculum of undergraduate students of TCSOL. Four research questions have been answered by investigating 448 undergraduate students of TCSOL and interviewing 40 undergraduate students using semi-open questions. Four main problems were identified in the current curriculum of undergraduate students of TCSOL, which have been the basis for in-depth discussion. This research can help colleges and universities achieve a thorough and comprehensive understanding of the current curriculum and teaching situation of undergraduate students of TCSOL in Zhejiang Province. The current problems of undergraduate students of TCSOL in Zhejiang Province have also been identified. Moreover, this research helps teachers of TCSOL understand the actual market demand for TCSOL talents to enable them to cultivate students who meet market requirement. As China rises, the Chinese will be favored by more people. Learning Chinese has become an irreversible trend. Given that the undergraduate curriculum of TCSOL is in its infancy in China, meeting the actual needs of teachers is difficult. Therefore, opportunities and challenges coexist, and various colleges and universities are exploring and conducting research so that the curriculum could be adapted to the promotion and internationalization of Chinese.

\section{ACKNOWLEDGMENTS}

This research supported by 2017 Zhejiang Provincial Education Planning Project (No. 2017SCG387) 


\section{REFERENCES}

[1] Deng, H.Y. (2018). Research on the Course Design and Teaching Methods of Chinese International Education in Universities. Course Education Research, 60(45), 12-15.

[2] Guo, Y.B. \& Sun, N.N. (2016). Research on Foreign Language Curriculum Design of Chinese International Education Major Based on Investigation. Journal of Liaoning Economic Management Cadre and Vocational Technological Institute, 12(1), $111-116$.

[3] Li, G. H. (2014). Framework of the International Curriculum System for Chinese Language. Chinese Language Teaching Newsletter, 10(2), 13-15.

[4] Liu, H. (2016). Optimizing the Curriculum Module Setting and Strengthening the Training of Comprehensive Ability-Analysis on the Training Mode of Chinese International Education Professionals from a Global Perspective. Journal of Weifang University, 12(1), 96-98.

[5] Liu, L.F. \& Jian, F.Q. (2017). Research on the Reform and Development of the International Education of Chinese Language in Local Universities in Ethnic Areas under the Background of Application Transformation--Taking Baise University's Core Course Construction and Reform of "Teaching Chinese as a Foreign Language" for Example. Comparative Study of Cultural Innovation, 12(10), 77-80.

[6] Ning, J. M. (2018). Rethinking International Chinese Education both as a Profession and an Academic Discipline. Chinese Journal of Language Policy and Planning, 18 (6), 6-16.

[7] Pan, Y.H., Li, Y.J., \& Chen, Z. (2016). "Three Transformations and One Speciality": A New Path for the Undergraduate Courses of Chinese International Education. Journal of Yunan Normal University (Teaching and Research on Chinese As A Foreign Language), 12(2), 32-36.

[8] Peng, Y. (2014). Innovation Research and Practice on the Curriculum System for the International Promotion of Chinese Language. Journal of Hunan Mass Media Vocational College, 11(6), 42-45.

[9] Shi, L. (2019). A Preliminary Study on the Undergraduate Professional Curriculum and Employment Guidance of Chinese International Education-Taking Southwest University for Nationalities as an Example. Journal of Xichang University (Social Science Edition), 12(1), 114-118.

[10] Wang, H.Y (2019). A Preliminary Study on the Curriculum Setting of Chinese International Education Major in Local Applied Undergraduate Universities-Taking Jinzhong University as an Example. Sinogram Culture, 38(19) 33-35.

[11] Wang, S.H. (2017). Thoughts on the Curriculum Setting of the Undergraduate Courses of Chinese International Education-Based on the Discussion of the "Catalogues and Introduction of Undergraduate Courses in Higher Education (2012). Journal of Yunan Normal University (Teaching and Research on Chinese As A Foreign Language), 12(1). 23-31.

[12] Wang, Z.D. (2011). Research and Practice on Training Model and Curriculum System of the Chinese as a Foreign Language Talent in the Local Higher Normal University. Education and Teaching Research, 25(1), 72-76.

[13] Wen, Q. F. (2019). From TESOL TO TCSOL: Reflections and suggestions. Chinese Teaching in the world, 12(3), $291-299$.

[14] Xing, Y.G., \& Wan, S.P. (2014). Reflections on the Construction of the Curriculum System for the Undergraduate Program of Chinese International Education. Tianjin Federation of Social Sciences, 12(2), 24-36.

[15] Yang, F. (2019). Grasp the "three levels" and stick to the "three steps"-Modular Reform and Practice of the "Chinese +" Curriculum System of the Undergraduate Chinese International Education. Modern Education Science, 24(19), 20-24.

[16] Zhao, J.Y (2020). An Analysis of the Curriculum Design of the Master of Chinese International Education from the Perspective of "One Belt and One Road". The Science Education Article Collects, 12(1), 55-60.

Yong Wu was born in Shaoxing, China. She is currently an associate professor in the English faculty, Zhejiang Yuexiu University of Foreign Languages, Shaoxing, China. Her research interests include psycholinguistics, second language learning and teaching. 